The FASEB Journal express article 10.1096/fj.04-1728fje. Published online December 29, 2005.

\title{
Absence of CC chemokine receptor 8 enhances innate immunity during septic peritonitis
}

\author{
Akihiro Matsukawa,* Shinji Kudoh,* Gen-ichiro Sano, ${ }^{\ddagger}$ Takako Maeda,* Takaaki Ito,* \\ Nicholas W. Lukacs, ${ }^{\dagger}$ Cory M. Hogaboam, ${ }^{\dagger}$ Steven L. Kunkel, ${ }^{\dagger}$ and Sergio A. Lira ${ }^{\ddagger}$ \\ *Department of Pathology and Experimental Medicine, Graduate School of Medical Sciences, \\ Kumamoto University, Kumamoto, Japan; Department of Pathology, University of Michigan \\ Medical School, Ann Arbor, Michigan; ${ }^{\ddagger}$ Immunobiology Center, Mount Sinai School of \\ Medicine, New York, New York \\ Corresponding author: Akihiro Matsukawa, Department of Pathology and Experimental \\ Medicine, Graduate School of Medical Sciences, Kumamoto University, 1-1-1, Honjo, \\ Kumamoto 860-8556, Japan. E-mail: matsu@kaiju.medic.kumamoto-u.ac.jp
}

\section{ABSTRACT}

An effective clearance of microbes is crucial in host defense during infection. In the present study, we demonstrate that CC chemokine receptor 8 (CCR8) skews innate immune response during septic peritonitis induced by cecal ligation and puncture (CLP). CCR8 was expressed in resident peritoneal macrophages and elicited leukocytes during CLP in the wild-type CCR8 ${ }^{+/+}$ mice. $\mathrm{CCR}^{-/-}$mice were resistant to CLP-induced lethality relative to CCR8 ${ }^{+/+}$mice, and this resistance was associated with an augmented bacterial clearance in CCR8 ${ }^{-/}$mice. In vitro, peritoneal macrophages from $\mathrm{CCR}^{-/-}$mice, but not neutrophils, exhibited enhanced bactericidal activities relative to those from $\mathrm{CCR}^{+/+}$mice. Upon stimulation with the bacterial component LPS, elevated levels of superoxide generation, lysosomal enzyme release, and nitric oxide generation, effector molecules for bacterial killing were detected in $\mathrm{CCR}^{-/-}$macrophages relative to $\mathrm{CCR}^{+/+}$macrophages. In addition, $\mathrm{CCR} 8^{-/-}$macrophages produced significantly higher levels than $\mathrm{CCR}^{+/+}$macrophages of several cytokines and chemokines known to augment bactericidal activities of leukocytes that include TNF- $\alpha$, IL-12, macrophage-derived chemokine (MDC/CCL22), macrophage inflammatory protein (MIP)-2, and KC. Altogether, these results indicate that CCR8 may have a negative impact on host defense during septic peritonitis, providing a new paradigm for the role of CCR8 in innate immunity.

Key words: sepsis • macrophages • cytokines $\bullet$ inflammation

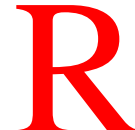

ecruitment of leukocytes into inflammatory foci is the first-line of host defense in infection, enabling the host to achieve effective and efficient removal of microbes (1). _ crucial in this process, attracting and activating leukocytes that bear classified into four subtypes, depending on which chemokine subfamily is recognized $(2,3)$. Recent studies have demonstrated that chemokine receptors are preferentially expressed on 
specific leukocyte subpopulations. For example, Th1 cells express CC chemokine receptor (CCR)5 and CXC chemokine receptor (CXCR)3, whereas Th2 cells are associated with CCR3, CCR4, and CCR8 (4).

In addition to being expressed on in vitro polarized Th2 cells, CCR8 has been detected in T cells from asthma patients, a Th2-dominant disorder (5). CCR8 ${ }^{-1-}$ mice demonstrate impaired Th2 response in animal models of granuloma and allergic airway inflammation where Th2 cells play a central role (6), albeit the role of CCR8 in allergic airway disease is controversial $(7,8)$. Thus, studies to date in the context of CCR8 have focused attention on adaptive immunity. However, CCR8 was originally identified on monocytes (9), and T cell activation-specific gene 3 (TCA3)/CCL1, a ligand for CCR8, is chemotactic for monocytes/macrophages and neutrophils $(10,11)$. Because infiltrating macrophages and neutrophils are essential for bacterial killing in infection (12), including septic peritonitis $(13,14)$, it seemed possible that CCR8 may play a role in the innate immunity.

To identify the functional role of CCR8 in bacterial infection, we used CCR8 ${ }^{-/}$mice and examined the innate immune response during septic peritonitis induced by cecal ligation and puncture (CLP). CLP is a clinically relevant model of intra-abdominal sepsis, which develops slowly and simulates a polymicrobial enteric insult similar to that seen in patients with colonic perforations (15). In the present study, we demonstrate for the first time that mice with CCR8 deficiency are resistant to CLP-induced lethality, resulting from augmented innate immune responses. These results provide a new paradigm for the role of CCR8 in host defense during sepsis.

\section{MATERIALS AND METHODS}

\section{Mice}

$\mathrm{CCR}^{-/-}$mice (6) were backcrossed 10 generations onto the C57BL/6 mice (Charles River Laboratories, Wilmington, MA). Age- and sex-matched C57BL/6 mice were used as wild-type $\mathrm{CCR}^{+/+}$mice. All chemokine receptors examined (CCR1-11, CXCR1-6, XCR1, CX3CR1, DARC, and D6), but CCR8 were similarly expressed in $\mathrm{CCR}^{-/-}$mice relative to $\mathrm{CCR} 8^{+/+}$mice as assessed by quantitative PCR using specific primers for each chemokine receptor (data not shown). Cell populations in the resident peritoneal cells were similar between CCR8 ${ }^{+/+}$and $\mathrm{CCR}^{-/-}$mice as estimated by flow cytometry (F4/80 positive cells, 36-40\%; B 220 positive cells, 20-24\%; Thy1.2 positive cells, 11-16\%). Mice were used in all experiments under specific pathogen-free conditions.

\section{In vivo experimental protocol}

CLP surgery was performed as described elsewhere $(13,15)$. In brief, mice were anesthetized and the cecum was exposed, ligated with a 3-0 silk suture below the ileocecal valve, and punctured through and through once with a 21-gauge needle. To determine mice survival, CLPmice were monitored for 7 days after CLP. In the different set of experiments, CLP mice were anesthetized, bled, and killed at appropriate intervals after CLP. The peritoneal cavities were washed with $2 \mathrm{ml}$ of sterile saline, and the lavage fluids were harvested under sterile conditions. Peritoneal lavage fluids and peripheral blood (10 $\mu \mathrm{l})$ from each mouse were serially diluted with 
sterile saline, and $5 \mu \mathrm{l}$ of each dilution was plated on trypticase soy agar (TSA) plates with $5 \%$ sheep blood and incubated overnight at $37^{\circ} \mathrm{C}$, after which the number of aerobic bacteria colonies was counted. The remaining lavage fluids were centrifuged at $6000 \mathrm{~g}$ for $1 \mathrm{~min}$ at $4^{\circ} \mathrm{C}$, and cell-free peritoneal fluids were stored at $-80^{\circ} \mathrm{C}$. Cell pellets were resuspended in saline, and the cell numbers were counted in a hemocytometer. Differential cell analyses were made by Diff-Quik staining of the smear slides. Smear slides were also used for immunocytochemistry. In other experiments, mice were intraperitoneal inoculated with live bacteria $\left(1 \times 10^{8} \mathrm{CFU} / \mathrm{mouse}\right)$ recovered from $\mathrm{CCR}^{+/+}$mice undergone CLP. The peritoneal lavage fluids at $24 \mathrm{~h}$ after the inoculation were serially diluted with sterile saline, and $5 \mu \mathrm{l}$ of each dilution was plated on TSAblood plates, incubated overnight at $37^{\circ} \mathrm{C}$, and the CFU was counted.

\section{Quantitative PCR}

Chemokine receptor expression was quantitated by quantitative RT-PCR. Briefly, total RNA was isolated from resident macrophages, treated with DNase I and reverse-transcribed using Random Hexamer as primers and reverse transcriptase. cDNA (25 ng) was amplified in a mixture of SYBR Green PCR Master Mix (Applied Biosystems, Foster City, CA) and primers using GeneAmp $7700\left(50^{\circ} \mathrm{C}\right.$ for $2 \mathrm{~min}, 95^{\circ} \mathrm{C}$ for $10 \mathrm{~min}, 40$ cycles of $95^{\circ} \mathrm{C}$ for $15 \mathrm{~s}$, and $60^{\circ} \mathrm{C}$ for 1 min; Applied Biosystems). CCR8 primers are sense, 5'TGACCGACTACTACCCTGATTTCTT-3' and antisense, 5'-GCTGCCCCTGAGGAGGAA-3'. Target gene expression was shown as relative values compared with the amount of ubiquitin cDNA in samples. Ubiquitin primers are sense, 5'-TGGCTATTAATTATTCGGTCTGCAT-3' and antisense, 5'-GCAAGTGGCTAGAGTGCAGAGTAA-3'.

\section{Western blotting}

Cells were dissolved in Laemmli buffer $\left(1 \times 10^{6} / 50 \mu \mathrm{l}\right)$, sonicated, boiled, fractionated on SDSpolyacrylamide gel $(10 \mu \mathrm{l})$, and transferred to a nitrocellulose membrane. After blocking with TBS-T (Tris-buffered saline+0.1\% Tween-20) containing 5\% skim milk for $1 \mathrm{~h}$ at room temperature, the membrane was incubated with goat anti-murine CCR8 IgG (Alexis Biochemicals, San Diego, CA) overnight at $4^{\circ} \mathrm{C}$. After washing with TBS-T, the membrane was incubated with rabbit anti-goat Fab’ conjugated to peroxidase-labeled dextran polymer (Nichirei Co., Tokyo, Japan) for $1 \mathrm{~h}$ at room temperature and visualized with an enhanced chemiluminescence system (Cell Signaling Inc., Beverly, MA).

\section{Immunocytochemistry}

Cytospin preparations were fixed immediately in 100\% methanol. After blocking endogenous peroxidase using $0.3 \% \mathrm{H}_{2} \mathrm{O}_{2}$ in methanol, we rehydrated the slides in Tris-buffered saline (TBS) and blocked with $10 \%$ normal goat serum for $1 \mathrm{~h}$ at room temperature. The slides were incubated with goat anti-murine CCR8 IgG (Alexis Biochemicals) or control goat IgG at $5 \mu \mathrm{g} / \mathrm{ml}$ in TBS$1 \%$ BSA overnight at $4^{\circ} \mathrm{C}$. After being washed with TBS-tween $20(0.1 \%)$, the slides were incubated with rabbit anti-goat IgG conjugated to horseradish peroxidase (HRP)-labeled dextran polymer (EnVision plus, Peroxidase: DakoCytomation, Carpinteria, CA) for $30 \mathrm{~min}$ at room temperature. After washing, the reaction was developed with diaminobenzidine (Sigma, St. Louis, MO). Counter-staining was done with hematoxylin. 


\section{In vitro phagocytic and killing activities of leukocytes}

Peritoneal cells were harvested from non-treated mice, suspended in antibiotic-free RPMI medium containing $10 \% \mathrm{FCS}$, and cultured for $1 \mathrm{~h}$ at $37^{\circ} \mathrm{C}$ in two 24 -well culture dishes $\left(1.5 \times 10^{6} /\right.$ well). Non-adherent cells were removed, and the adherent macrophages were infected with $1 \times 10^{6} \mathrm{CFU}$ of live bacteria, which were recovered from the peritoneum of CCR $8^{+/+}$mice at $24 \mathrm{~h}$ after CLP. After $1 \mathrm{~h}$-incubation, the wells were washed out to remove unphagocytized bacteria, and the cells in one plate were lysed with sterile $0.5 \%$ Triton X-100 for bacterial phagocytosis assay. Wells in the other plate were replaced with pre-warmed fresh medium and incubated for an additional $2 \mathrm{~h}$, after which the cells were lysed with $0.5 \%$ Triton X-100 for bacterial killing assay (14). The lysates were serially diluted, plated on TSA-blood plates, and incubated overnight at $37^{\circ} \mathrm{C}$, and the numbers of aerobic colonies were counted. In other experiments, infiltrating leukocytes were harvested at $6 \mathrm{~h}$ after intraperitoneal injection of $1 \mathrm{ml}$ of $4 \%$ thioglycollate (Difco Laboratories, Detroit, MI). Neutrophils were isolated from the elicited leukocytes by Ficoll gradient centrifugation (neutrophil purity $>94 \%$ ). To determine in vitro bactericidal activities of neutrophils, a classical CFU assay was used with minor modifications (16). In brief, cells were infected with $1 \times 10^{6} \mathrm{CFU}$ of live bacteria recovered from CLP-mice. Control wells contained only bacteria. After being cultured for $4 \mathrm{~h}$ in a $5 \% \mathrm{CO}_{2}$ incubator, plates were placed at $-80^{\circ} \mathrm{C}$ for $30 \mathrm{~min}$ and cells were lysed by thawing. This did not affect bacteria viability, as determined in control experiments. The lysates were serially diluted, plated on TSA-blood plates, and incubated overnight at $37^{\circ} \mathrm{C}$, and the number of aerobic colonies was counted. Bactericidal activity was expressed as \% bacteria death $=[\mathrm{CFU}$ from control wells (without cells) - CFU from experimental wells]/[CFU from control wells (without cells) $] \times 100$.

\section{Cell culture}

Adherent macrophages from resident peritoneal cells $\left(1.5 \times 10^{6} /\right.$ well $)$ were cultured in RPMI 1640 supplemented with $10 \%$ FCS, glutamine, and antibiotics in a $5 \% \mathrm{CO}_{2}$ incubator with or without the bacterial component LPS (1 $\mu \mathrm{g} / \mathrm{ml}$, E. coli 0111, B4: Difco Laboratories, Detroit, MI). After $24 \mathrm{~h}$, the culture supernatants were harvested and centrifuged at $6000 \mathrm{~g}$ for $1 \mathrm{~min}$ at $4^{\circ} \mathrm{C}$, and cell-free supernatants were stored at $-80^{\circ} \mathrm{C}$. The culture supernatants were used for measurements of cytokines, lysosomal enzyme release, and nitric oxide (NO) production. The lysosomal enzyme release was determined by $\beta$-glucuronidase activity, according to the methods described previously (17). NO level was determined by measuring nitrite and nitrate, stable end products of nitric oxide metabolism, using Colorimetric enzymatic NO assay kit (Oxford Biomedical Research, Oxford, MI).

The superoxide production from cells was measured using the reduction of ferricytochrome c $(14,18)$. In brief, adherent peritoneal macrophages or peripheral neutrophils purified by Ficoll gradient centrifugation $\left(1 \times 10^{6} /\right.$ well) were cultured in phenol red-free RPMI 1640 containing cytochrome $c(1.3 \mathrm{mg} / \mathrm{ml}$, Sigma), and stimulated with LPS $(1 \mu \mathrm{g} / \mathrm{ml})$ for $30 \mathrm{~min}$, and the supernatants were measured spectrophotometrically at $550 \mathrm{~nm}$ as a function of ferricytochrome $c$ reduction. 


\section{Cytokine ELISAs}

Murine cytokines were measured using a standard method of sandwich ELISA, as described (19, 20). The captured antibodies, detection antibodies, and recombinant cytokines were purchased from R\&D Systems (Minneapolis, MN). The ELISAs used in this study did not cross-react with other murine cytokines available, and they consistently detected murine cytokine concentrations above $30 \mathrm{pg} / \mathrm{ml}$.

\section{Statistics}

Statistical significance was evaluated by ANOVA. In case of survival curve and CFU count, the data were analyzed by the log-rank test and Mann-Whitney test, respectively. A $P<0.05$ value was regarded as statistically significant. All data were expressed as mean \pm SEM.

\section{RESULTS}

\section{Expression of CCR8 in peritoneal leukocytes during CLP}

In our initial experiments, we examined whether CCR8 was expressed in peritoneal leukocytes during CLP. Freshly isolated peripheral blood mononuclear cells, purified by Ficoll gradient centrifugation, showed negligible level of CCR8 expression as estimated by RT-PCR and Western blot (data not shown). The CCR8 mRNA expression was detected in resident peritoneal macrophages from CCR8 ${ }^{+/+}$mice (Fig. $1 A$ ). Immunocytochemistry revealed that CCR8 protein was present on the resident macrophages (Fig. 1B). CCR8 was also detected in elicited leukocytes obtained from CCR8 ${ }^{+/+}$mice that underwent CLP as examined by Western blot (Fig. $\underline{1 C})$. At this time point, infiltrating macrophages and neutrophils were stained with anti-CCR8 IgG, and the overall staining intensity was stronger than resident macrophages (Fig. $1 B$ ). Thus, CCR8 was expressed in both resident macrophages and elicited leukocytes (macrophages and neutrophils) during CLP, but not in peripheral blood mononuclear cells, in CCR ${ }^{+/+}$mice. In contrast, resident peritoneal macrophages as well as elicited leukocytes during CLP from $\mathrm{CCR}^{-/-}$mice did not express CCR8 (Fig. $1 A, \underline{C}$ ). No positive staining was observed in CCR8 ${ }^{-/-}$ macrophages (not shown).

\section{$\mathrm{CCR8}^{-/-}$mice were resistant to CLP-induced lethality}

To determine the functional role of CCR8 in host defense during CLP, survival rates in CCR8 ${ }^{+/+}$ and $\mathrm{CCR}^{-/-}$mice were monitored after CLP. The data in Fig. 2 demonstrated that all CCR8 ${ }^{-/-}$ mice (23/23) survived for 2 days after CLP, whereas 12 out of $21 \mathrm{CCR}^{+/+}$mice were dead on day 2. Of the $23 \mathrm{CCR}^{-/-}$mice, 21 survived for 7 days; whereas only $5 \mathrm{CCR}^{+/+}$mice $(5 / 21)$ survived for 7 days $\left(P<0.0001\right.$, Fig. 2). These data clearly demonstrate that $\mathrm{CCR} 8^{-/}$mice are resistant to the lethality induced by CLP.

\section{Increased bacterial clearance in $\mathrm{CCR8}^{-1-}$ mice}

Bacterial burden is tightly associated with the mortality in the CLP model where infiltrating leukocytes play a central role $(13,14)$. To identify the basis whereby $\mathrm{CCR}^{-/-}$mice were resistant to CLP, bacterial burden and leukocyte infiltration in CLP-mice were investigated. 
Although bacterial burden at $6 \mathrm{~h}$ post CLP was unchanged between $\mathrm{CCR}^{+/+}$and CCR8 ${ }^{-/-}$mice, $\mathrm{CCR}^{-/-}$mice displayed an increased bacterial clearance at $24 \mathrm{~h}$ post CLP, as indicated by smaller numbers of recovered CFU counts in the peritoneum (Fig. 3A). The mean peritoneal $\mathrm{CFU}$ count in $\mathrm{CCR} 8^{-/-}$mice was a $10^{3}$-fold lower than that in $\mathrm{CCR} 8^{+/+}$mice. At this time point, bacteremia was observed in 4/16 of CCR $8^{+/+}$mice, but not in CCR8 ${ }^{-/-}$mice (0/13) (Fig. 3B). Enhanced bacterial clearance in $\mathrm{CCR}^{-/-}$mice was also observed when mice were intraperitoneally received live bacteria $\left(1 \times 10^{8} \mathrm{CFU} /\right.$ mouse $)$ recovered from $\mathrm{CCR}^{+/+}$mice undergone CLP (Fig. 3C). On the other hand, no statistical differences were found in the number of infiltrating neutrophils and macrophages at 6 and $24 \mathrm{~h}$ after CLP between CCR $8^{+/+}$and $\mathrm{CCR}^{-/-}$mice (not shown). Thus, $\mathrm{CCR} 8^{-/-}$mice cleared bacteria much more effectively than $\mathrm{CCR}^{+/+}$mice without augmenting the leukocyte infiltration, suggesting that bactericidal activities of leukocytes may be augmented in $\mathrm{CCR}^{-/-}$mice.

\section{Augmented innate immune response in $\mathrm{CCR8}^{-/-}$macrophages}

We, therefore, examined the phagocytic and killing activities of peritoneal macrophages and neutrophis from $\mathrm{CCR}^{+/+}$and $\mathrm{CCR}^{-/-}$mice. As shown in Table 1 , the CFU counts inside macrophages after $1 \mathrm{~h}$ culture were similar between $\mathrm{CCR}^{+/+}{ }^{\text {and CCR }}{ }^{-/-}$mice, suggesting an equal phagocytic activity of the cells. After an additional $2 \mathrm{~h}$ culture, the CFU counts inside $\mathrm{CCR}^{-/-}$macrophages were significantly lower than $\mathrm{CCR}^{+/+}$macrophages (Table 1). In contrast, in vitro bactericidal activities of neutrophils were not augmented in CCR8 ${ }^{-/-}$ neutrophils. Effector molecules for bacterial killing were subsequently examined in the culture supernatants of LPS-stimulated peritoneal macrophages, which included superoxide anion $\left(\mathrm{O}_{2}{ }^{-}\right)$ generation, lysosomal enzyme ( $\beta$-glucronidase) release, and NO production (21). As shown in Fig. 4A, CCR $8^{-/}$macrophages produced higher levels of these molecules than $\mathrm{CCR}^{+/+}$ macrophages. Superoxide generation in $\mathrm{CCR}^{-/-}$neutrophils was not augmented upon stimulation with LPS (data not shown). Thus, $\mathrm{CCR}^{-/-}$macrophages, but not neutrophils, exhibited enhanced bactericidal activities when compared with CCR8 ${ }^{+/+}$cells.

Next we investigated the ability of peritoneal macrophages to secrete cytokines known to augment the bactericidal activities of leukocytes. For this, CCR8 ${ }^{+/+}$and $\mathrm{CCR} 8^{-/-}$macrophages were cultured in the presence or absence of LPS, and cytokine levels in the supernatants were measured. The data in Fig. $4 \mathrm{~B}$ demonstrated that $\mathrm{CCR}^{-/-}$macrophages produced significantly higher levels of TNF $\alpha$, IL-12, and macrophage-derived chemokine (MDC)/CCL22 than CCR8 ${ }^{+/+}$ macrophages. Elevated levels of the neutrophil activating chemokines macrophage inflammatory protein (MIP)-2 and KC were also detected in the supernatants of $\mathrm{CCR}^{-/-}$macrophages relative to CCR8 ${ }^{+/+}$macrophages (Fig. 4B). Higher production of cytokines and chemokines by CCR8 ${ }^{-/-}$ macrophages could represent an important mechanism favoring bacterial removal from the $\mathrm{CCR}^{-/-}$hosts.

\section{Altered cytokine response and prevention of renal injury in $\mathrm{CCR8}^{-/-}$mice}

Effective bacteria killing in $\mathrm{CCR}^{-/-}$mice may lead to decreased systemic response followed by CLP. Subsequently, plasma levels of several cytokines and organ damage after CLP were investigated. The data in Fig. 6 demonstrated that CCR $8^{-/-}$mice displayed 60 and $41 \%$ decreases 
in plasma levels of TNF $\alpha$ and IL-12, respectively, although they were not statistically significant. However, anti-inflammatory cytokine IL-10 and IL-13 were significantly augmented in $\mathrm{CCR}^{-/-}$mice, compared with $\mathrm{CCR}^{+/+}$mice (Fig. 5). Kidney is a major target organ during sepsis, and the dysfunction can be fatal to the host (23). CLP caused an elevation in the level of blood urea nitrogen (BUN) and creatinine in $\mathrm{CCR}^{+/+}$mice, representing renal injury in this model (Fig. 6). In CCR8 ${ }^{-/-}$mice, levels of BUN and creatinine after CLP were comparable with those from untreated mice (Fig. 6). Thus, $\mathrm{CCR}^{-/-}$mice evaded renal injury induced by CLP, an event that was associated with an altered cytokine balance in favor of anti-inflammatory effects.

\section{DISCUSSION}

Effective host defense against bacterial infection is dependent on the recruitment and activation of phagocytic cells (21), which is governed by chemokine and chemokine receptors (2, 3). In the present study, we provide evidence suggesting that the chemokine receptor CCR8 may have a novel and unexpected role that is important in innate immunity. Most of the work on this receptor thus far has focused on its potential role in adaptive immunity. The findings presented here now implicate CCR8 in innate immunity and constitute the first example of negative regulation of innate immunity by a chemokine receptor.

The increased survival of the CCR8 ${ }^{-/-}$mice in the CLP model of sepsis was associated with an enhanced bactericidal activity of the $\mathrm{CCR}^{-/-}$macrophages. In this context, altered neutrophil function may account for the different degree of bacterial clearance during CLP, as approximately two-thirds of infiltrating leukocytes were neutrophils. Despite the presence of CCR8 on infiltrating neutrophils, in vitro superoxide generation as well as bacteria killing of neutrophils were not augmented in $\mathrm{CCR}^{-/-}$mice relative to $\mathrm{CCR} 8^{+/+}$mice. Thus, neutrophils did not appear to directly contribute to the altered bacterial clearance in CCR8 ${ }^{-/-}$mice. Although macrophages may influence bactericidal activity of neutrophils, allowing $\mathrm{CCR}^{-/-}$mice to achieve effective innate immunity, our present data suggest that ablation of CCR8 function on macrophages appears to have an unexpected positive impact on innate immune response during septic peritonitis.

The results in the present study raise several questions, such as: Are the local levels of the murine CCR8 ligand TCA3 altered during peritonitis, and if so, does TCA3 favor development of septic peritonitis? Our results suggest that direct ligation of CCR8 by TCA3 does not seem to favor the development of septic peritonitis in wild-type CCR8 ${ }^{+/+}$mice. Appreciable levels of TCA3 were not detected in the peritoneum during CLP $(0.05 \pm 0.02$ and $0.20 \pm 0.07 \mathrm{ng} / \mathrm{ml}, 6$ and $24 \mathrm{~h}$ post-CLP, respectively, 6 mice each). TCA3 (10-100 ng/ml) did not reduce cytokine production from LPS-stimulated macrophages or in vitro bactericidal activities of peritoneal macrophages. Furthermore, intraperitoneal injection of TCA3 $(1 \mu \mathrm{g} / \mathrm{mouse})$ at the time of CLPsurgery did not induce increased bacterial load in the peritoneum or bacteremia during CLP (our own unpublished observations). Other CCR8 ligand(s) may provide bacteria with environmental niche. In this context, thymus and activation-regulated cytokine (TARC/CCL17) and macrophage inflammatory protein-1 $\beta$ (MIP-1 $\beta$ /CCL4) can be the possible ligand (24), but others demonstrate that these chemokines do not bind CCR8 at physiologically relevant concentrations (25). CCR8 may be constitutively active, as this has been reported for some viral chemokine receptors $(26,27)$ and could be relevant in this particular model. Endogenous 
antagonist(s) may cause the negative regulation, however, no such molecules have been identified to date in humans or mice. MC148, a virally encoded CCR8 antagonist, has been identified in the genome of the human poxvirus molluscum contagiosum (28). Viral chemokines such as vMIP-II and vMCC-1 act as potent antagonists without inducing signaling (29), which suggests the existence of molecules with similar properties in humans and mice. Identification of CCR8 ligands or molecules with antagonistic activity against CCR8 remains to be established.

Finally, and perhaps more importantly, why are the CCR ${ }^{-/-}$macrophages more efficient at mounting bactericidal responses? Could CCR8 interfere with innate immune responses? In the present study, we showed that no appreciable level of CCR8 was found in peripheral blood mononuclear cells, but the expression was evident in peritoneal resident macrophages. CCR8 expression was augmented in the elicited leukocytes during CLP. Consistent with our observations, Trebst et al. have recently demonstrated that CCR8 expression on monocytes is upregulated in response to monocyte/macrophage-activating stimuli, despite no appreciable CCR8 expression in peripheral blood monocytes (30). Thus, CCR8 expression appears to be associated with macrophage differentiation and/or activation status. An attractive hypothesis is that CCR8 may interfere with innate immune responses by regulating differentiation of macrophages. Studies done by Qu et al. suggest that this may be occurring in the CCR8 ${ }^{-1-}$ mice. Their results indicate that different sets of monocytes are recruited into the peritoneum of $\mathrm{CCR}^{+/+}$and $\mathrm{CCR}^{-/-}$mice after intraperitoneal challenge of thioglycollate. Nearly half of the monocytes in $\mathrm{CCR}^{+/+}$mice differentiated into DC after 2 days culture in the presence of GM-CSF; whereas only a small number of monocytes from $\mathrm{CCR}^{-/}$did so (31). These are intriguing observations because it has been shown that monocytes/macrophages that differentiate into DC-like cells mount poor innate immune responses $(22,32)$. Thus, signaling through CCR8 may actually control the differentiation of macrophages and favor the accumulation in the peritoneum of $\mathrm{CCR}^{-/-}$macrophages with higher bactericidal activities. Up-regulated LPS-induced cytokine response in $\mathrm{CCR}^{-/-}$macrophages could be associated with the developmental fate of macrophages.

Failure in restricting the invading pathogens to a localized area of tissue results in an overwhelming systemic response via an enhanced cytokine/chemokine production, leading to systemic inflammatory response syndrome (SIRS) (33). This is likely the mechanism whereby $\mathrm{CCR}^{-/-}$mice are resistant to septic peritonitis induced by CLP. In this model, the CCR8 ${ }^{-/}$mice evaded renal injury during CLP as evidenced by clinical chemistry. Of interest was the observation that plasma cytokine response during CLP in $\mathrm{CCR}^{-/-}$mice was balanced in favor of anti-inflammatory effects. Although effective bacteria clearance in CCR8 ${ }^{-1-}$ mice appears to be primarily responsible for the reduced production of TNF $\alpha$ and IL-12, augmented production of anti-inflammatory cytokines is expected to play a role in decreasing the level of TNF $\alpha$ and IL12 , possibly contributing to an alleviation of renal injury. Studies are required to elucidate how CCR8 regulates cytokine balance during CLP.

We have thus far elucidated important roles of chemokine-chemokine receptor system in an innate immunity during CLP. For instance, CC chemokines CCL2/MCP-1, CCL3/MIP-1 $\alpha$, CCL6/C10, and CCL22/MDC are beneficial to the septic peritonitis by augmenting an innate immune response $(13,14,20,34,35)$. Thus, inflammatory responses governed by chemokines are primarily beneficial to the host defense during CLP. However, an excessive inflammation 
appears to be pathologic, as neutralization of macrophage inflammatory protein (MIP)-2 and its receptor CXCR2, which plays a crucial role in neutrophil infiltration/activation, is deleterious to the host $(36,37)$. The host response in the innate immunity is controlled by IL-10, IL-12, and IL13 (20, 38, 39), in which Stat proteins are important in balancing the cytokine responses $(19,40)$. The results in the present study provide a new paradigm for the role of chemokine-chemokine receptor system in an innate immunity. As shown here, ablation of CCR8 function enhanced innate immunity in a model of sepsis, resulting in an alleviation of systemic impact during septic peritonitis. Sepsis and septic shock are conditions associated with high morbidity and mortality, and few effective therapies exist to treat these diseases. The results reported here suggest that therapeutic intervention targeting CCR8 may provide a novel strategy for the treatment of sepsis and septic shock.

\section{ACKNOWLEDGMENTS}

We thank Berlin AA (Department of Pathology, University of Michigan Medical School) for his technical assistance. This work was supported in part by Grant-in-Aid for Scientific Research on Priority Areas from The Ministry of Education, Culture, Sports, Science and Technology, Japan, by National Institutes of Health Grants R01-HL031237 and P50-HL074024, and by the grant provided by The Ichiro Kanehara Foundation. Sergio Lira is an Irene Diamond Associate Professor in Immunology and this work was funded in part by a grant from the Irene Diamond Fund.

\section{REFERENCES}

1. Hoffmann, J. A., Kafatos, F. C., Janeway, C. A., and Ezekowitz, R. A. (1999) Phylogenetic perspectives in innate immunity. Science 284, 1313-1318

2. Baggiolini, M. (2001) Chemokines in pathology and medicine. J. Intern. Med. 250, 91-104

3. Zlotnik, A., and Yoshie, O. (2000) Chemokines: a new classification system and their role in immunity. Immunity 12, 121-127

4. Sallusto, F., Mackay, C. R., and Lanzavecchia, A. (2000) The role of chemokine receptors in primary, effector, and memory immune responses. Annu. Rev. Immunol. 18, 593-620

5. Panina-Bordignon, P., Papi, A., Mariani, M., Di Lucia, P., Casoni, G., Bellettato, C., Buonsanti, C., Miotto, D., Mapp, C., Villa, A., et al. (2001) The C-C chemokine receptors CCR4 and CCR8 identify airway T cells of allergen-challenged atopic asthmatics. J. Clin. Invest. 107, 1357-1364

6. Chensue, S. W., Lukacs, N. W., Yang, T. Y., Shang, X., Frait, K. A., Kunkel, S. L., Kung, T., Wiekowski, M. T., Hedrick, J. A., Cook, D. N., et al. (2001) Aberrant in vivo T helper type 2 cell response and impaired eosinophil recruitment in CC chemokine receptor 8 knockout mice. J. Exp. Med. 193, 573-584 
7. Chung, C. D., Kuo, F., Kumer, J., Motani, A. S., Lawrence, C. E., Henderson, W. R., Jr., and Venkataraman, C. (2003) CCR8 is not essential for the development of inflammation in a mouse model. J. Immunol. 170, 581-587

8. Goya, I., Villares, R., Zaballos, A., Gutierrez, J., Kremer, L., Gonzalo, J.-A., Varona, R., Carramolino, L., Serrano, A., Pallares, P., Criado, L. M., Kolbeck, R., Torres, M., Coyle, A. J., Gutierrez-Ramos, J.-C., Martinez-A, C., and Marquez, G. (2003) Absence of CCR8 Does Not Impair the Response to Ovalbumin-Induced Allergic Airway Disease. J Immunol 170, 2138-2146

9. Tiffany, H. L., Lautens, L. L., Gao, J. L., Pease, J., Locati, M., Combadiere, C., Modi, W., Bonner, T. I., and Murphy, P. M. (1997) Identification of CCR8: a human monocyte and thymus receptor for the CC chemokine I-309. J. Exp. Med. 186, 165-170

10. Devi, S., Laning, J., Luo, Y., and Dorf, M. E. (1995) Biologic activities of the betachemokine TCA3 on neutrophils and macrophages. J. Immunol. 154, 5376-5383

11. Luo, Y., Laning, J., Devi, S., Mak, J., Schall, T. J., and Dorf, M. E. (1994) Biologic activities of the murine beta-chemokine TCA3. J. Immunol. 153, 4616-4624

12. Aderem, A., and Underhill, D. M. (1999) Mechanisms of phagocytosis in macrophages. Annu. Rev. Immunol. 17, 593-623

13. Matsukawa, A., Hogaboam, C. M., Lukacs, N. W., Lincoln, P. M., Strieter, R. M., and Kunkel, S. L. (1999) Endogenous monocyte chemoattractant protein-1 (MCP-1) protects mice in a model of acute septic peritonitis: cross-talk between MCP-1 and leukotriene B4. $J$. Immunol. 163, 6148-6154

14. Matsukawa, A., Hogaboam, C. M., Lukacs, N. W., Lincoln, P. M., Evanoff, H. L., and Kunkel, S. L. (2000) Pivotal Role of the CC Chemokine, Macrophage-Derived Chemokine, in the Innate Immune Response. J. Immunol. 164, 5362-5368

15. Fink, M. P., and Heard, S. O. (1990) Laboratory models of sepsis and septic shock. J. Surg. Res. 49, 186-196

16. Leijh, P. C., van den Barselaar, M. T., and van Furth, R. (1977) Kinetics of phagocytosis and intracellular killing of Candida albicans by human granulocytes and monocytes. Infect. Immun. 17, 313-318

17. Gallin, J. I., Fletcher, M. P., Seligmann, B. E., Hoffstein, S., Cehrs, K., and Mounessa, N. (1982) Human neutrophil-specific granule deficiency: a model to assess the role of neutrophil-specific granules in the evolution of the inflammatory response. Blood 59, 13171329

18. Markert, M., Andrews, P. C., and Babior, B. M. (1984) Measurement of O2- production by human neutrophils. The preparation and assay of NADPH oxidase-containing particles from human neutrophils. Methods Enzymol. 105, 358-365 
19. Matsukawa, A., Kaplan, M. H., Hogaboam, C. M., Lukacs, N. W., and Kunkel, S. L. (2001) Pivotal role of signal transducer and activator of transcription (Stat) 4 and Stat6 in the innate immune response during sepsis. J. Exp. Med. 193, 679-688

20. Matsukawa, A., Hogaboam, C. M., Lukacs, N. W., Lincoln, P. M., Evanoff, H. L., Strieter, R. M., and Kunkel, S. L. (2000) Expression and contribution of endogenous IL-13 in an experimental model of sepsis. J. Immunol. 164, 2738-2744

21. Babior, B. M., Hoyal, C. R., Lehrer, R. I., and Ganz, T. (2001) Antimicrobial activity of leukocytes. In Physiology of inflammation (Ley, K., ed) pp. 189-203, Oxford University Press, New York

22. Buettner, M., Meinken, C., Bastian, M., Bhat, R., Stossel, E., Faller, G., Cianciolo, G., Ficker, J., Wagner, M., Rollinghoff, M., et al. (2005) Inverse correlation of maturity and antibacterial activity in human dendritic cells. J. Immunol. 174, 4203-4209

23. Astiz, M. E., and Rackow, E. C. (1998) Septic shock. Lancet 351, 1501-1505

24. Bernardini, G., Hedrick, J., Sozzani, S., Luini, W., Spinetti, G., Weiss, M., Menon, S., Zlotnik, A., Mantovani, A., Santoni, A., et al. (1998) Identification of the CC chemokines TARC and macrophage inflammatory protein-1 beta as novel functional ligands for the CCR8 receptor. Eur. J. Immunol. 28, 582-588

25. Garlisi, C. G., Xiao, H., Tian, F., Hedrick, J. A., Billah, M. M., Egan, R. W., and Umland, S. P. (1999) The assignment of chemokine-chemokine receptor pairs: TARC and MIP-1 beta are not ligands for human CC-chemokine receptor 8. Eur. J. Immunol. 29, 3210-3215

26. Pleskoff, O., Casarosa, P., Verneuil, L., Ainoun, F., Beisser, P., Smit, M., Leurs, R., Schneider, P., Michelson, S., and Ameisen, J. C. (2005) The human cytomegalovirusencoded chemokine receptor US28 induces caspase-dependent apoptosis. Febs. J. 272, 4163-4177

27. Casarosa, P., Gruijthuijsen, Y. K., Michel, D., Beisser, P. S., Holl, J., Fitzsimons, C. P., Verzijl, D., Bruggeman, C. A., Mertens, T., Leurs, R., et al. (2003) Constitutive signaling of the human cytomegalovirus-encoded receptor UL33 differs from that of its rat cytomegalovirus homolog R33 by promiscuous activation of $\mathrm{G}$ proteins of the $\mathrm{Gq}$, Gi, and Gs classes. J. Biol. Chem. 278, 50010-50023

28. Luttichau, H. R., Stine, J., Boesen, T. P., Johnsen, A. H., Chantry, D., Gerstoft, J., and Schwartz, T. W. (2000) A highly selective CC chemokine receptor (CCR)8 antagonist encoded by the poxvirus molluscum contagiosum. J. Exp. Med. 191, 171-180

29. Dairaghi, D. J., Fan, R. A., McMaster, B. E., Hanley, M. R., and Schall, T. J. (1999) HHV8encoded vMIP-I selectively engages chemokine receptor CCR8. Agonist and antagonist profiles of viral chemokines. J. Biol. Chem. 274, 21569-21574 
30. Trebst, C., Staugaitis, S. M., Kivisakk, P., Mahad, D., Cathcart, M. K., Tucky, B., Wei, T., Rani, M. R., Horuk, R., Aldape, K. D., et al. (2003) CC chemokine receptor 8 in the central nervous system is associated with phagocytic macrophages. Am. J. Pathol. 162, 427-438

31. Qu, C., Edwards, E. W., Tacke, F., Angeli, V., Llodra, J., Sanchez-Schmitz, G., Garin, A., Haque, N. S., Peters, W., van Rooijen, N., et al. (2004) Role of CCR8 and other chemokine pathways in the migration of monocyte-derived dendritic cells to lymph nodes. J. Exp. Med. 200, 1231-1241

32. Xu, H., Kramer, M., Spengler, H. P., and Peters, J. H. (1995) Dendritic cells differentiated from human monocytes through a combination of IL-4, GM-CSF and IFN-gamma exhibit phenotype and function of blood dendritic cells. Adv. Exp. Med. Biol. 378, 75-78

33. Hack, C. E., Aarden, L. A., and Thijs, L. G. (1997) Role of cytokines in sepsis. Adv. Immunol. 66, 101-195

34. Steinhauser, M. L., Hogaboam, C. M., Matsukawa, A., Lukacs, N. W., Strieter, R. M., and Kunkel, S. L. (2000) Chemokine C10 promotes disease resolution and survival in an experimental model of bacterial sepsis. Infect. Immun. 68, 6108-6114

35. Matsukawa, A., Hogaboam, C. M., Lukacs, N. W., Lincoln, P. M., Strieter, R. M., and Kunkel, S. L. (2000) Endogenous MCP-1 influences systemic cytokine balance in a murine model of acute septic peritonitis. Exp. Mol. Pathol. 68, 77-84

36. Walley, K. R., Lukacs, N. W., Standiford, T. J., Strieter, R. M., and Kunkel, S. L. (1997) Elevated levels of macrophage inflammatory protein 2 in severe murine peritonitis increase neutrophil recruitment and mortality. Infect. Immun. 65, 3847-3851

37. Ness, T. L., Hogaboam, C. M., Strieter, R. M., and Kunkel, S. L. (2003) Immunomodulatory role of CXCR2 during experimental septic peritonitis. J. Immunol. 171, 3775-3784

38. Steinhauser, M. L., Hogaboam, C. M., Lukacs, N. W., Strieter, R. M., and Kunkel, S. L. (1999) Multiple roles for IL-12 in a model of acute septic peritonitis. J. Immunol. 162, 5437-5443

39. Steinhauser, M. L., Hogaboam, C. M., Kunkel, S. L., Lukacs, N. W., Strieter, R. M., and Standiford, T. J. (1999) IL-10 is a major mediator of sepsis-induced impairment in lung antibacterial host defense. J. Immunol. 162, 392-399

40. Matsukawa, A., Takeda, K., Kudo, S., Maeda, T., Kagayama, M., and Akira, S. (2003) Aberrant inflammation and lethality to septic peritonitis in mice lacking STAT3 in macrophages and neutrophils. J. Immunol. 171, 6198-6205

Received March 11, 2004; accepted October 18, 2005. 


\section{Table 1}

\section{Phagocytic and killing activities of macrophages in vitro}

\begin{tabular}{|c|c|c|}
\hline Incubation $(\mathbf{h})^{\mathbf{a}}$ & $\mathrm{CCR8}^{+/+}$Macrophages & CCR8 $^{-/-}$Macrop \\
\hline 1 & $23.0 \pm 3.2$ & $24.3 \pm 2.3$ \\
\hline 3 & $13.8 \pm 2.9$ & $5.9 \pm 0.9^{\ddagger}$ \\
\hline
\end{tabular}

Killing rate $(\%)$

${ }^{a}$ Resident peritoneal macrophages were infected with bacteria recovered from CLP mice. After $1 \mathrm{~h}$ incubation, the wells were extensively washed and the cells were lysed with $0.5 \%$ Triton X-100 for phagocytic activity. Wells were replaced with fresh medium and cultured for an additional $2 \mathrm{~h}$, after which the cells were lysed with $0.5 \%$ Triton X-100 for killing activity. The lysates were serially diluted and placed on TSA blood agar plates, and CFU within the cells were determined. Data were expressed as CFU $\left(\times 10^{3}\right) / \mathrm{ml}($ mean $\pm \mathrm{SE}) .{ }^{\mathrm{b}} \mathrm{Killing}$ rate $=[1-(\mathrm{CFU}$ at $3 \mathrm{~h} / \mathrm{CFU}$ at $1 \mathrm{~h})] \times 100$. The data are representative of the two individual experiments $(n=6)$. $\$ P<0.05$, when compared with CCR $8^{+/+}$macrophages (two-tailed MannWhitney test). 
Fig. 1

A

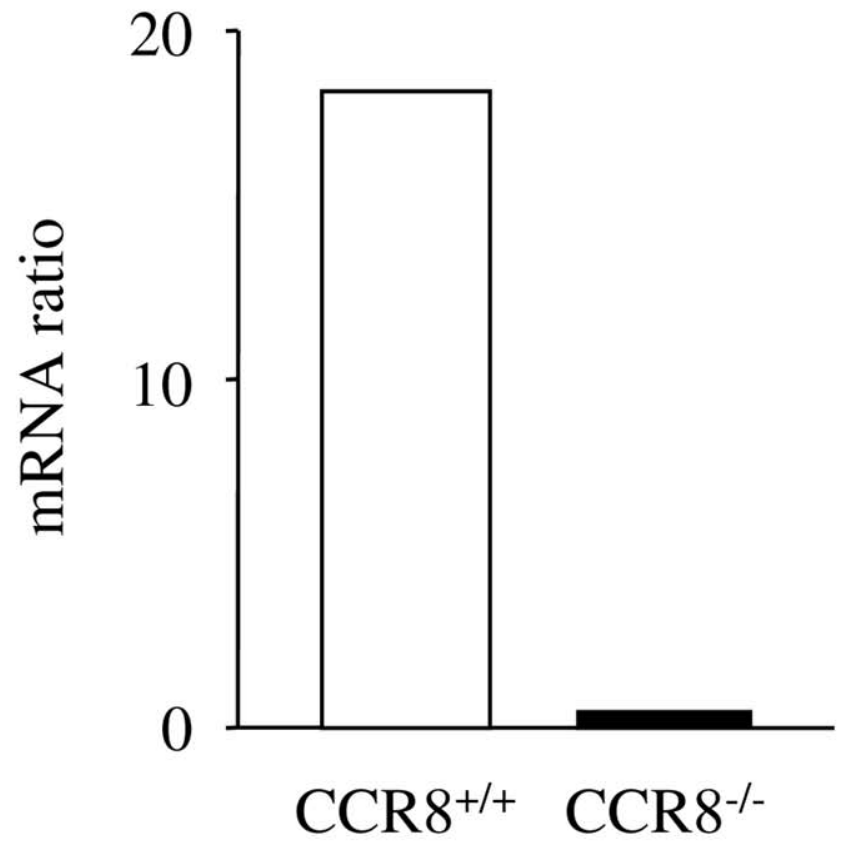

CCR8

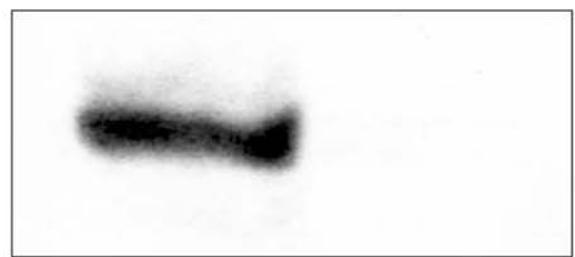

$\mathrm{CCR}^{+/+} \mathrm{CCR}^{-/-}$
B
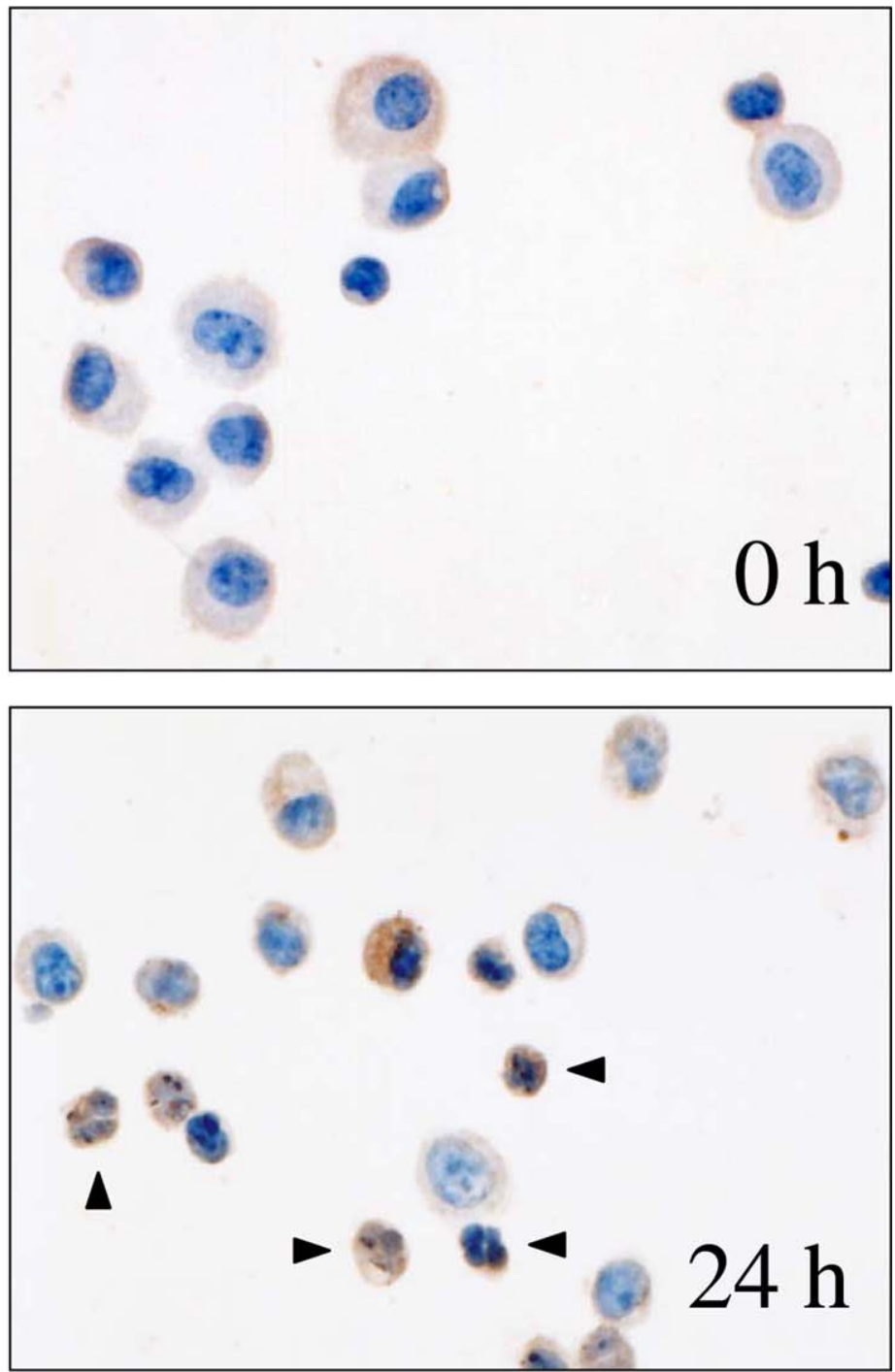

Figure 1. CCR8 is expressed in resident and elicited leukocytes during CLP. A) mRNA was isolated from resident peritoneal macrophages from $\mathrm{CCR} 8^{+/+}$and $\mathrm{CCR} 8^{-/-}$mice and subjected to quantitative RT-PCR. Data were mean from five mice. $\boldsymbol{B})$ Resident peritoneal macrophages $(0 \mathrm{~h})$ and exudate cells at $24 \mathrm{~h}$ post-CLP were harvested from CCR ${ }^{+/+}$ mice, and the cells were stained with anti-CCR8 IgG. A representative photograph. Arrowheads indicate infiltrating neutrophils. Original magnification $\times 400$. C) Peritoneal exudate cells from $\mathrm{CCR} 8^{+/+}$and $\mathrm{CCR} 8^{-/-}$mice were harvested at $24 \mathrm{~h}$ after CLP, and the lysates were immunoblotted with anti-CCR8 IgG. Representative data. 
Fig. 2

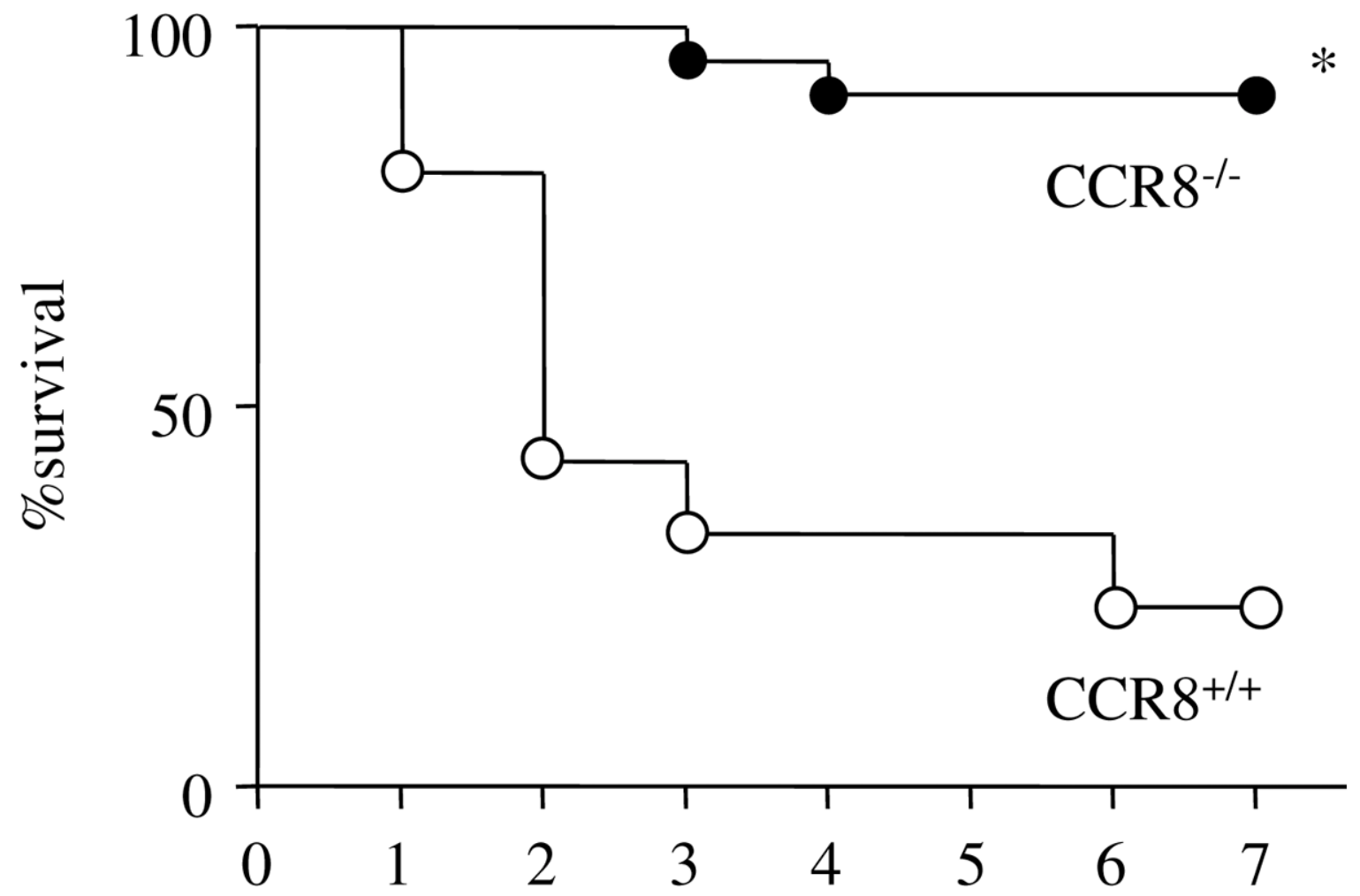

Figure 2. Mice lacking CCR8 are resistant to CLP-induced lethality. The survival rates in $\mathrm{CCR} 8^{+/+}$and $\mathrm{CCR} 8^{-/-}$mice were monitored for 7 days after CLP ( 21 and 23 mice, respectively). Three different experiments were performed, and the data were pooled. The results were very similar in individual experiments. ${ }^{*} P<0.0001 \mathrm{vs}$. CCR $8^{+/+}$mice. 
Fig. 3
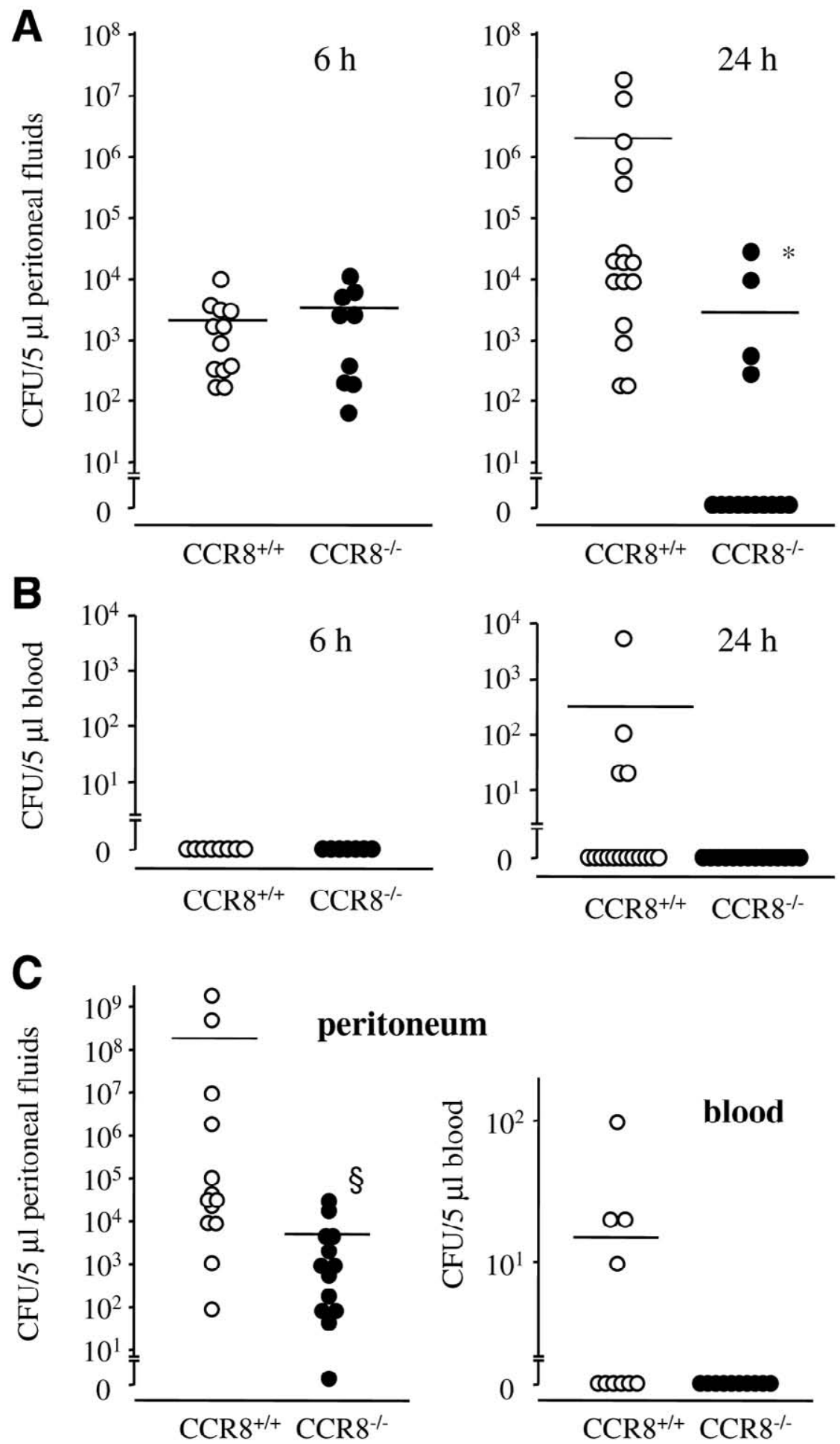

Figure 3. Enhanced bacterial clearance in $\mathrm{CCR} 8^{-1-}$ mice. $\left.\boldsymbol{A}, \boldsymbol{B}\right)$ At 6 and $24 \mathrm{~h}$ after CLP, mice were anesthetized, bled, and euthanized, and the peritoneal fluids were harvested. Peritoneal fluids $(10 \mu \mathrm{l})(\boldsymbol{A})$ and peripheral blood $(\boldsymbol{B})$ were serially diluted, and $5 \mu \mathrm{l}$ of each dilution was plated on TSA blood agar plates. Twenty-eight $\mathrm{CCR} 8^{+/+}$mice $(6 \mathrm{~h}: 12 \mathrm{mice}$; $24 \mathrm{~h}: 16$ mice) and $23 \mathrm{CCR}^{-/-}$mice (6 h: 9 mice; $24 \mathrm{~h}: 14$ mice) were used. $C$ ) Mice were intraperitoneally received live bacteria $\left(1 \times 10^{8} \mathrm{CFU} /\right.$ mouse) recovered from $\mathrm{CCR}^{+/+}$mice undergone CLP. At $24 \mathrm{~h}$ after the inoculation, mice were anesthetized, bled, and euthanized, and the peritoneal fluids were harvested. Peritoneal fluids (10 $\mu$ l) (13 mice each) and peripheral blood (10 mice each) were serially diluted, and $5 \mu 1$ of each dilution was plated on TSA blood agar plates. Line represents mean $\mathrm{CFU}$ count. ${ }^{\S} P<0.01 .{ }^{*} P<0.0001$ vs. $\mathrm{CCR} 8^{+/+}$mice. 
Fig. 4

A

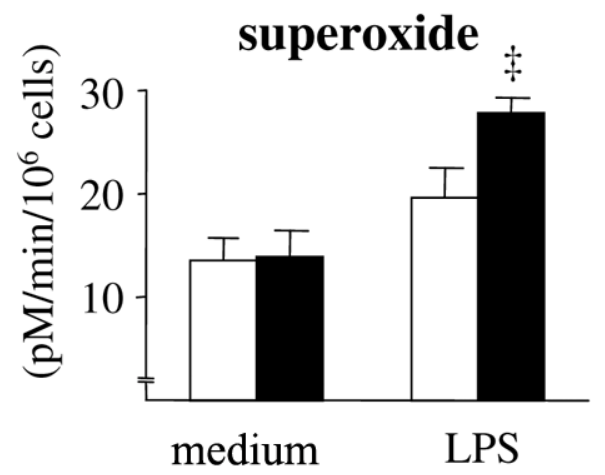

$\beta$-glucronidase

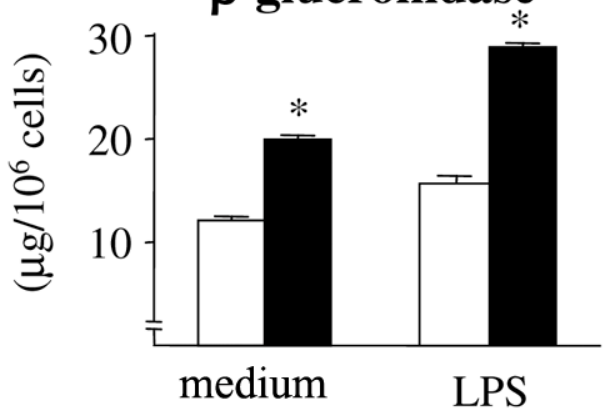

nitrite/nitrate

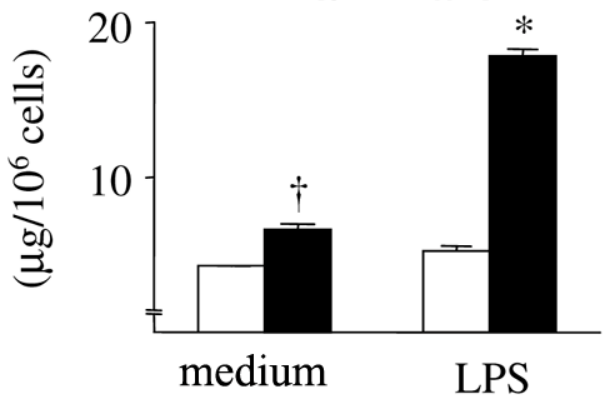

TNF $\alpha$

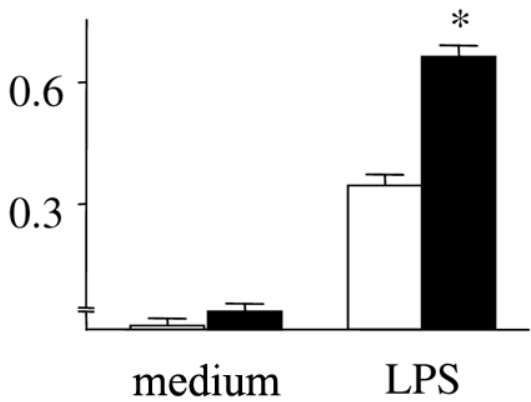

MDC

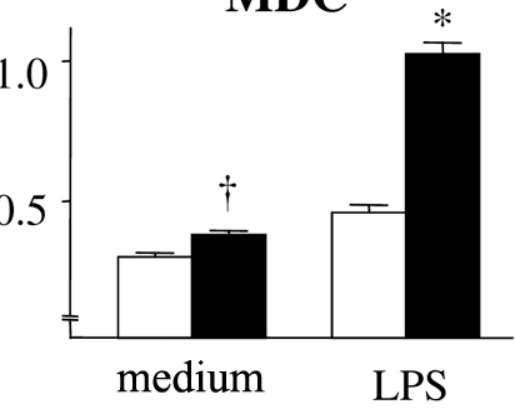

KC

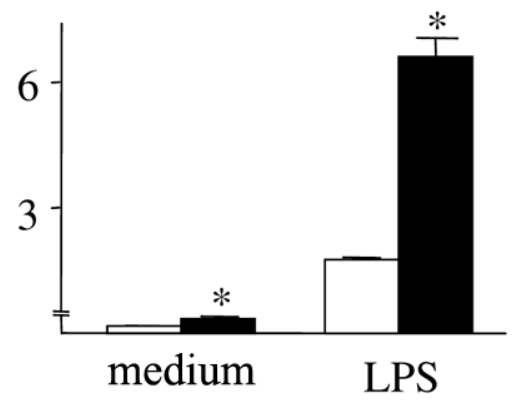

IL-12

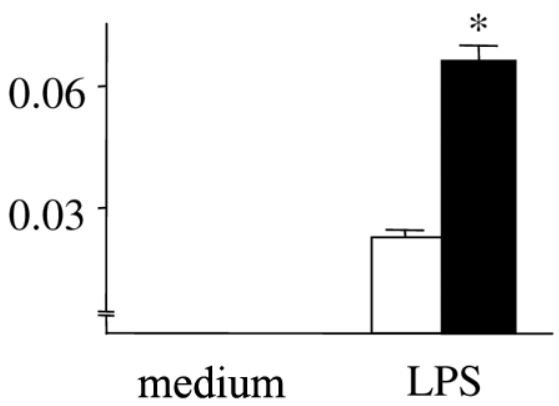

MIP-2

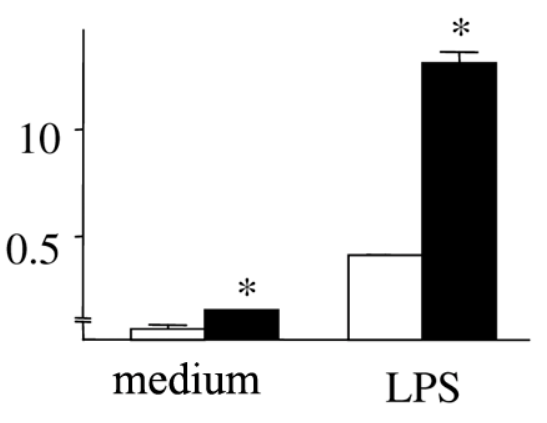

$\square \mathrm{CCR}^{+/++}$ CCR8 ${ }^{-1}$

Figure 4. Augmented macrophage function in $\mathrm{CCR}^{-/-}$mice. Peritoneal cells were harvested from $\mathrm{CCR} 8^{+/+}$and $\mathrm{CCR} 8^{-/-}$ mice; the cells $\left(1.5 \times 10^{6}\right.$ cells $)$ were incubated for $1 \mathrm{~h}$ at $37^{\circ} \mathrm{C}$ and non-adherent cells were removed. $\left.\boldsymbol{A}\right)$ For superoxide generation, the adherent macrophages were stimulated with LPS $(1 \mu \mathrm{g} / \mathrm{ml})$ for $30 \mathrm{~min}$, and the cultures were assayed. For $\beta$-glucuronidase release and nitric oxide production, the adherent macrophages were cultured with LPS ( $1 \mu \mathrm{g} / \mathrm{ml}) \mathrm{for} 24 \mathrm{~h}$. B) The adherent macrophages were stimulated with LPS $(1 \mu \mathrm{g} / \mathrm{ml})$ for $24 \mathrm{~h}$ at $37^{\circ} \mathrm{C}$, and cytokines and chemokines in the supernatants were measured. ${ }^{\ddagger} P<0.05 .{ }^{\dagger} P<0.001 .{ }^{*} P<0.0001$ vs. $\mathrm{CCR} 8^{+/+}$macrophages. 
Fig. 5
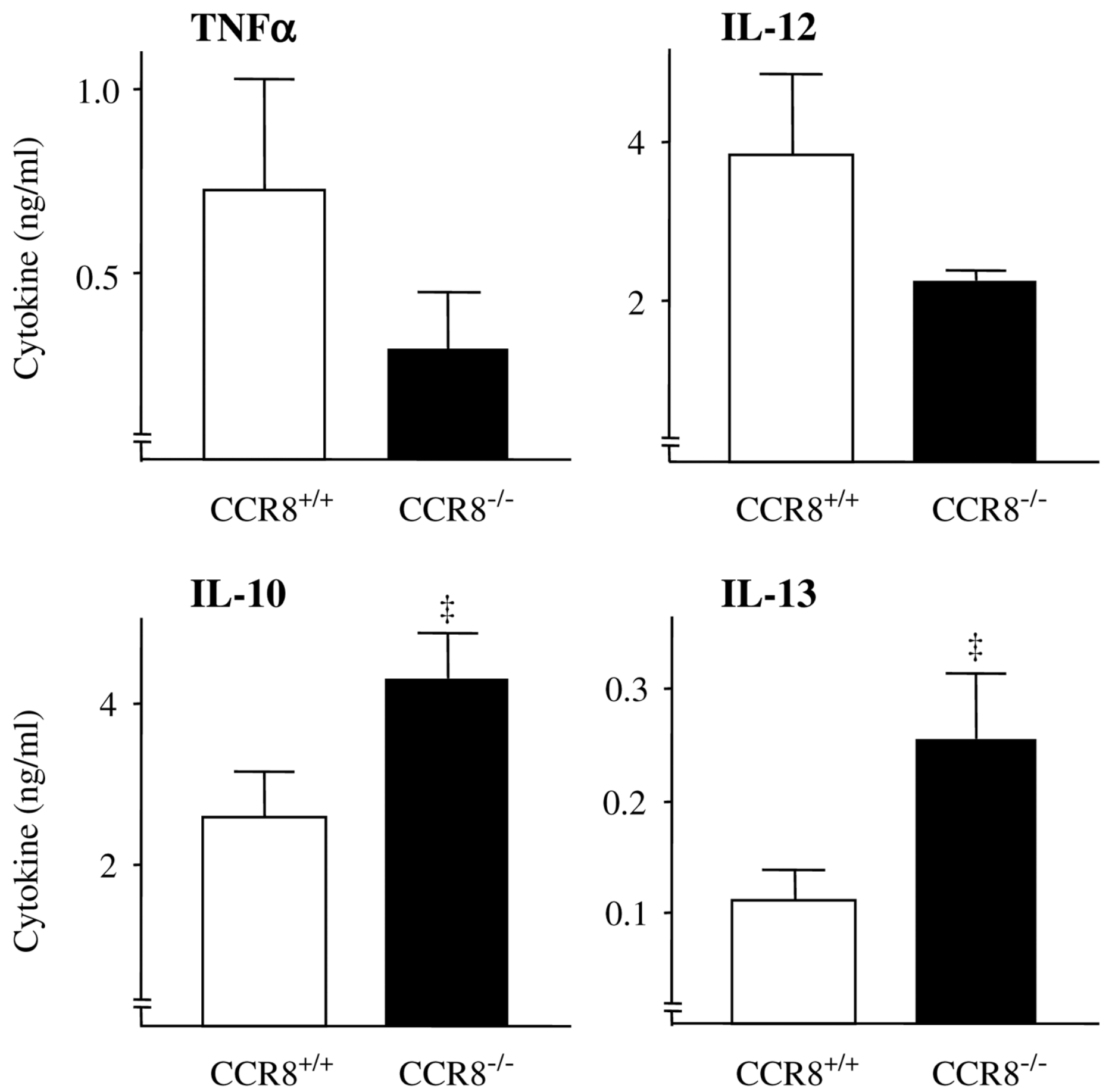

Figure 5. Altered cytokine response during CLP. At $24 \mathrm{~h}$ after CLP, CCR $8^{+/+}$and CCR $8^{-1-}$ mice $(8$ mice each) were euthanized and bled, and the plasma were harvested. Plasma levels of TNF- $\alpha$, IL-10, IL-12, and IL-13 were measured. ${ }^{\ddagger} P$ $<0.05$ vs. $\mathrm{CCR} 8^{+/+}$mice. 
Fig. 6

BUN

\section{$(\mathrm{mg} / \mathrm{dL})$}

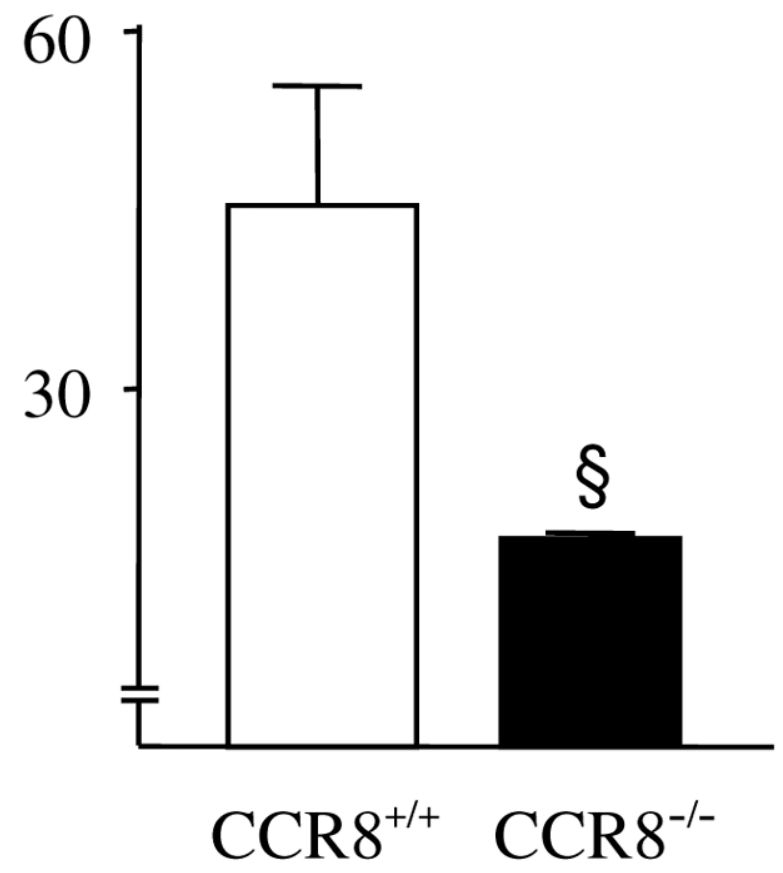

Creatinine

$(\mathrm{mg} / \mathrm{dL})$

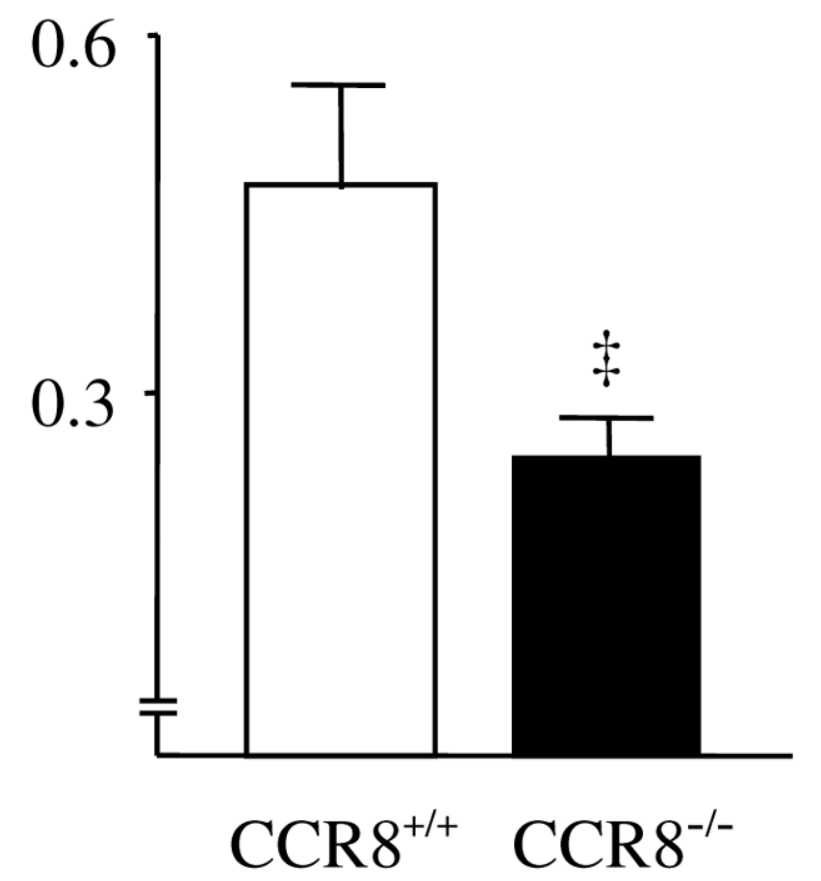

Figure 6. $\mathrm{CCR} 8^{-/-}$mice ameliorate renal injury induced by CLP. At $24 \mathrm{~h}$ after CLP, CCR $8^{+/+}$and CCR $8^{-/}$mice $(8$ mice each) were euthanized and bled, and the plasma were harvested. The amounts of BUN and creatinine in the plasma were measured. ${ }^{\ddagger} P<0.05,{ }^{\S} P<0.01$ vs. $C C R 8^{+/+}$mice. Dotted line represents the mean data obtained from untreated mice (5 mice each). 